

\title{
Content
}

- Introduction

- Loss of coolant accidents LOCA

- Secondary hydriding

- QUENCH-LO Experiments

- Results

- Radiography

- Tomography

- Conclusions 

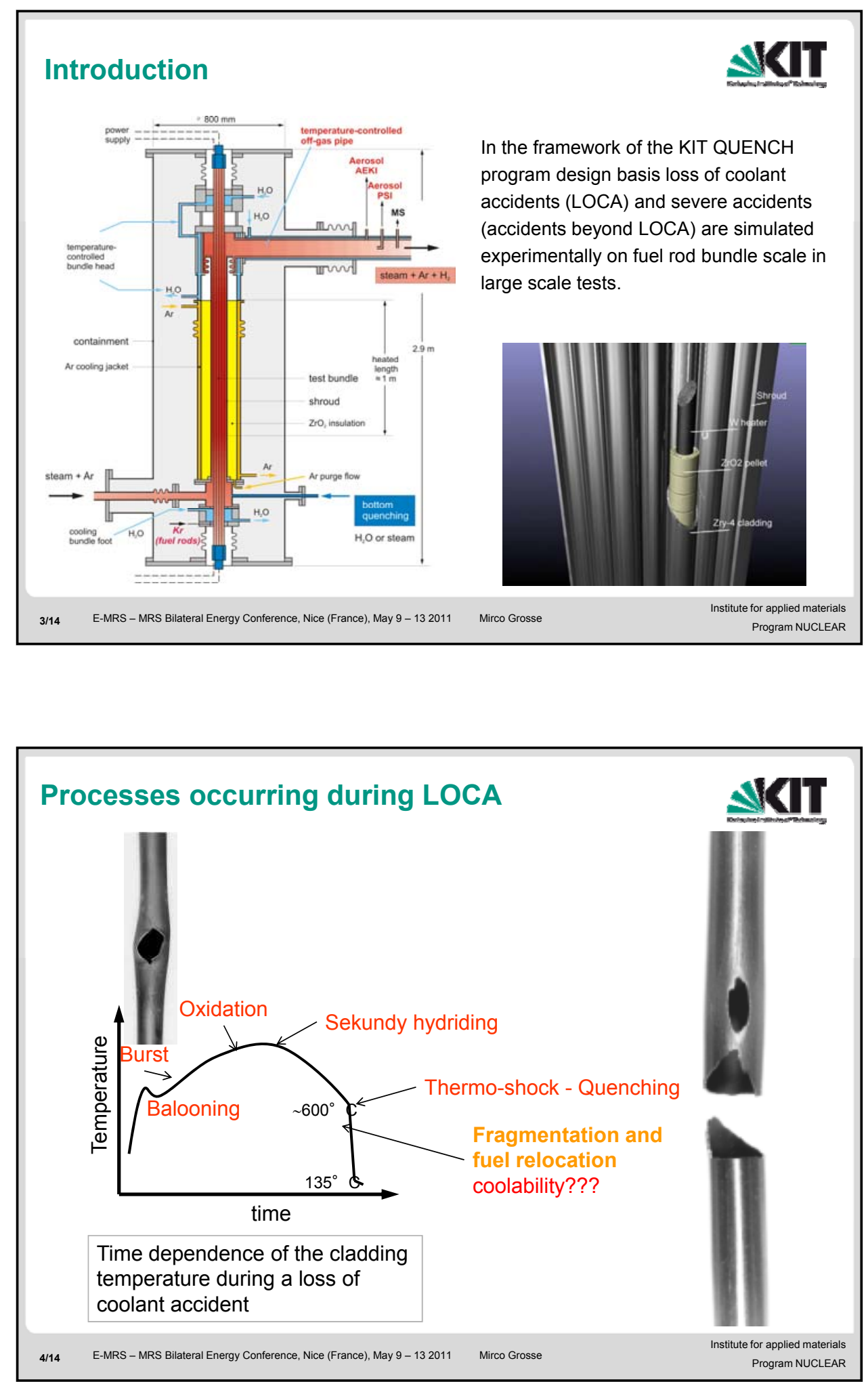

KIT - University of the State of Baden-Wuerttemberg and National Laboratory of the Helmholtz Association 


\section{Sekundary hydriding}

\section{$\$ \mathbf{V I I}$}
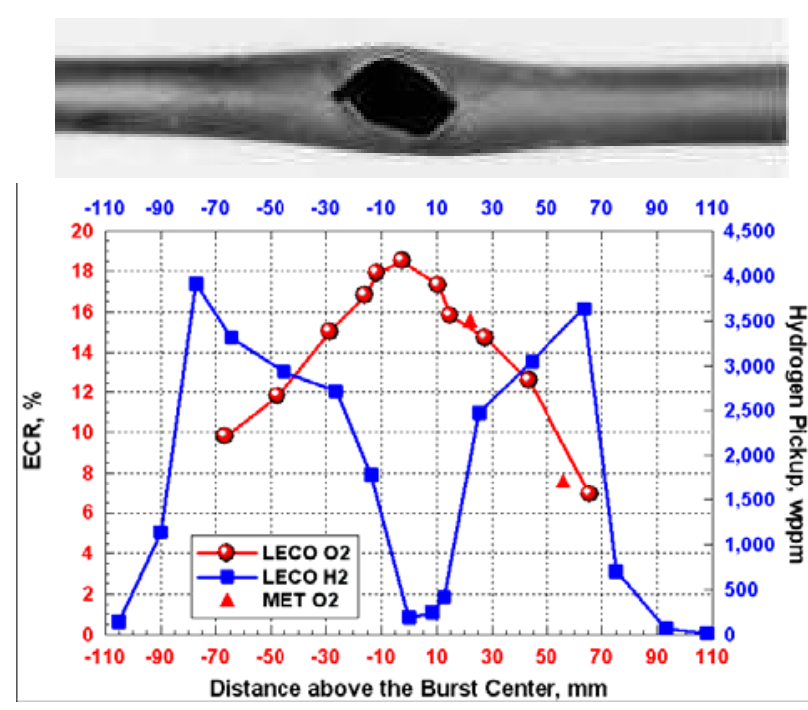

Influence on mechanical propoerties?

\section{QUENCH-L0 (commissioning test)}

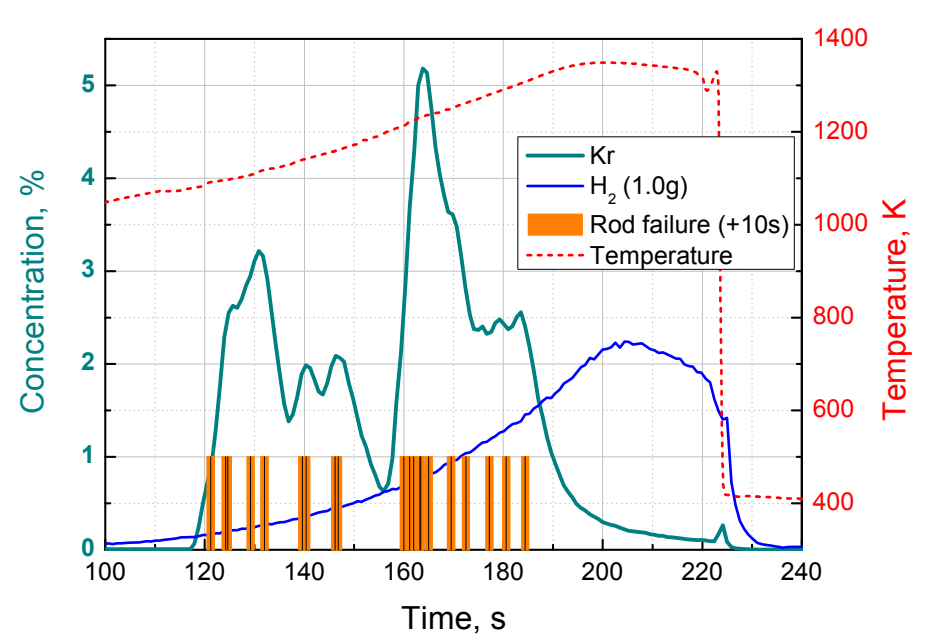

6/14 E-MRS - MRS Bilateral Energy Conference, Nice (France), May $9-132011$ 


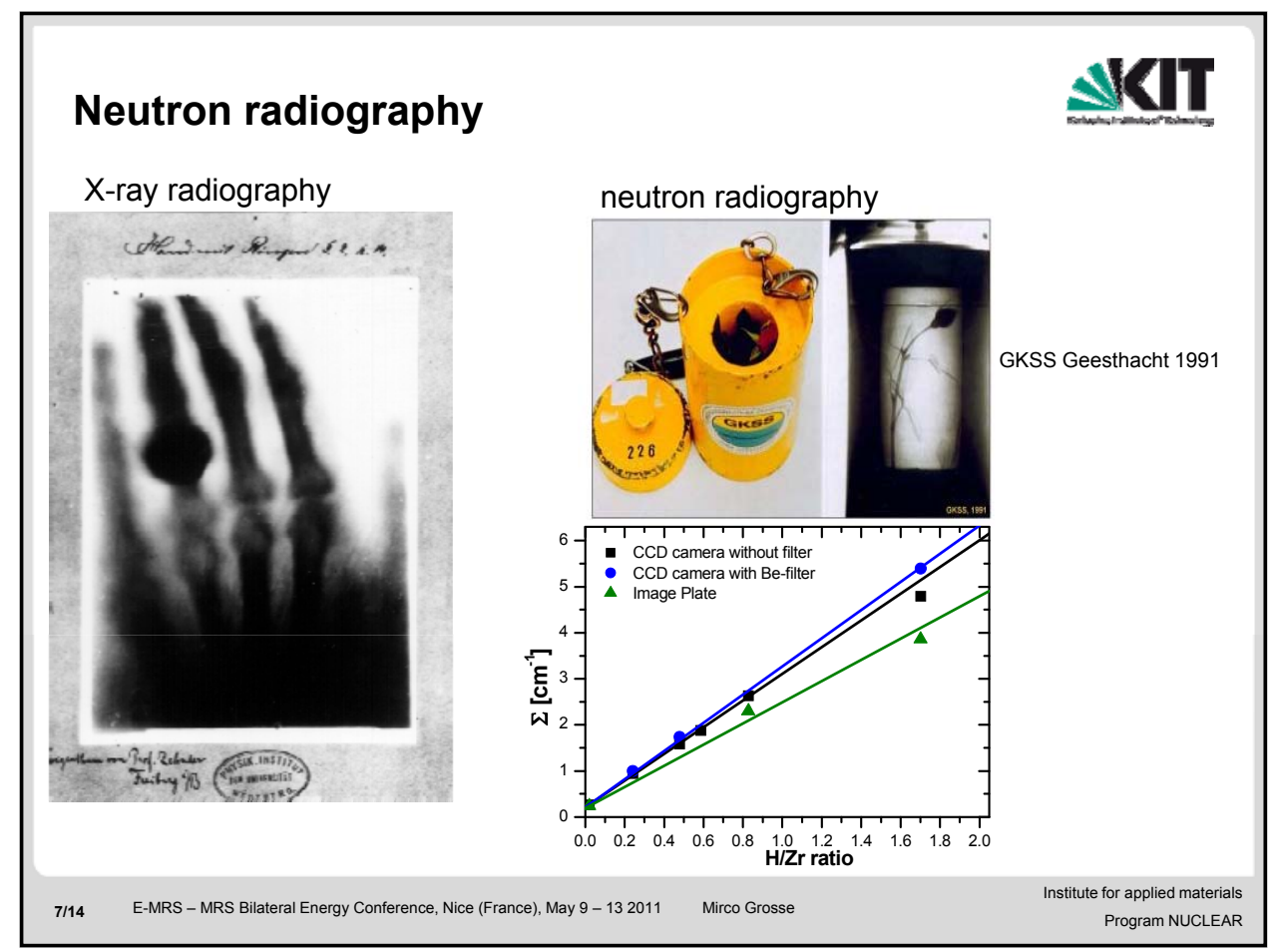

\section{Experiments}

- ICON facility (SINQ, PSI Villigen, $\mathrm{CH}$ )

- 13.-16.08.2010 (radiography)

- 09.-17.09.2010 (tomography)

- Illumination time per image: $300 \mathrm{~s}$ (radiography)

$625 \times 90 \mathrm{~s}$ (tomography)

- Spatial resolution: $\quad \sim 23 \mu \mathrm{m} \quad$ (radiography)

$\sim 46 \mu \mathrm{m} \quad$ (tomography)

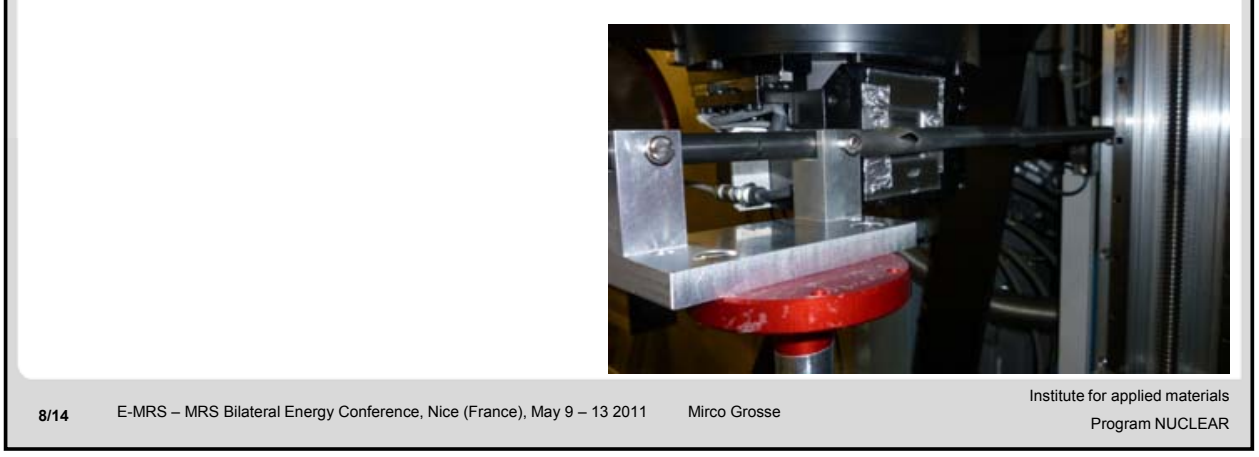

KIT - University of the State of Baden-Wuerttemberg and

National Laboratory of the Helmholtz Association 


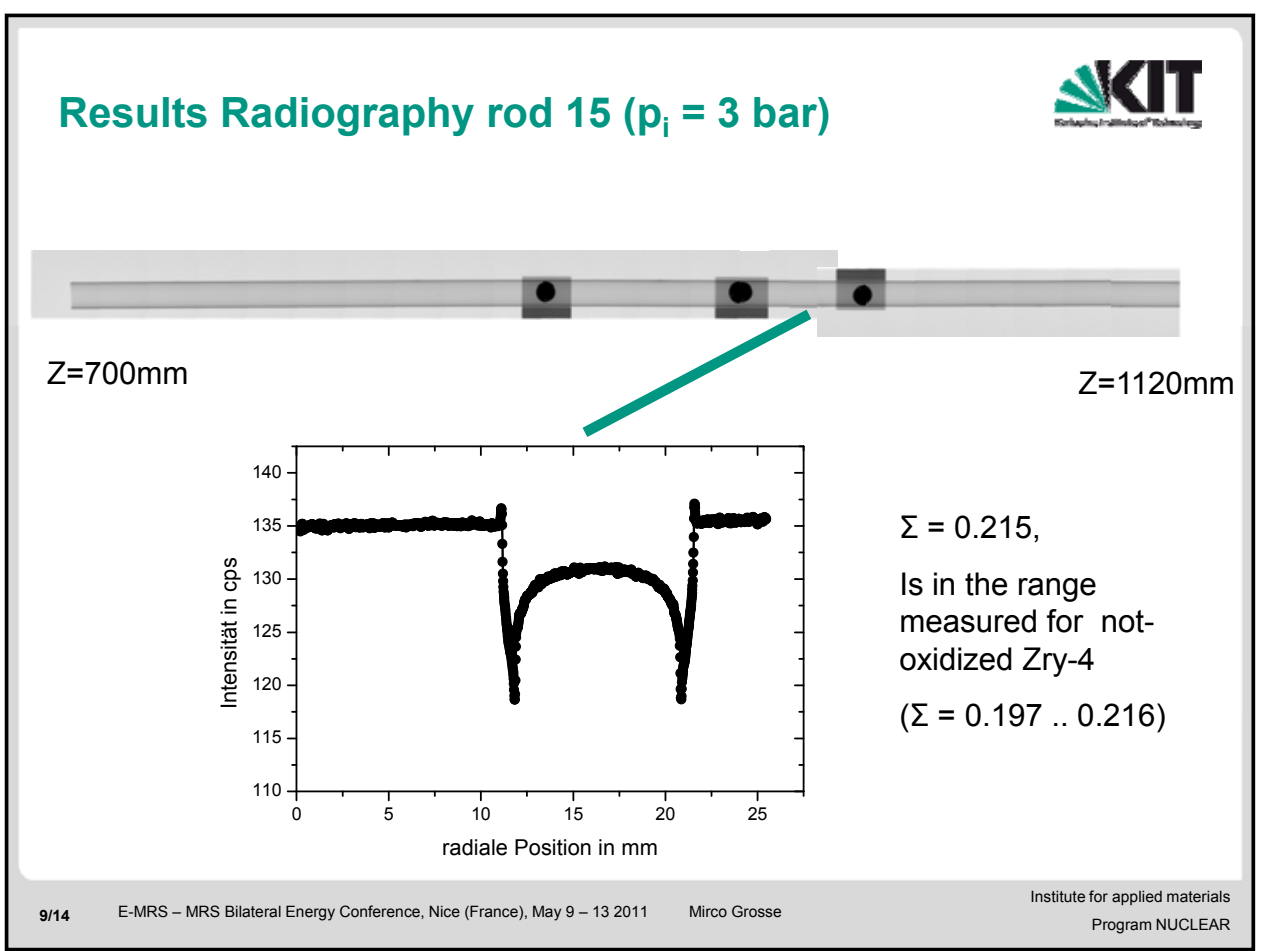

Results Radiography rod $03\left(p_{i}=55\right.$ bar, $\left.\Delta t=104 \mathrm{~s}\right)$
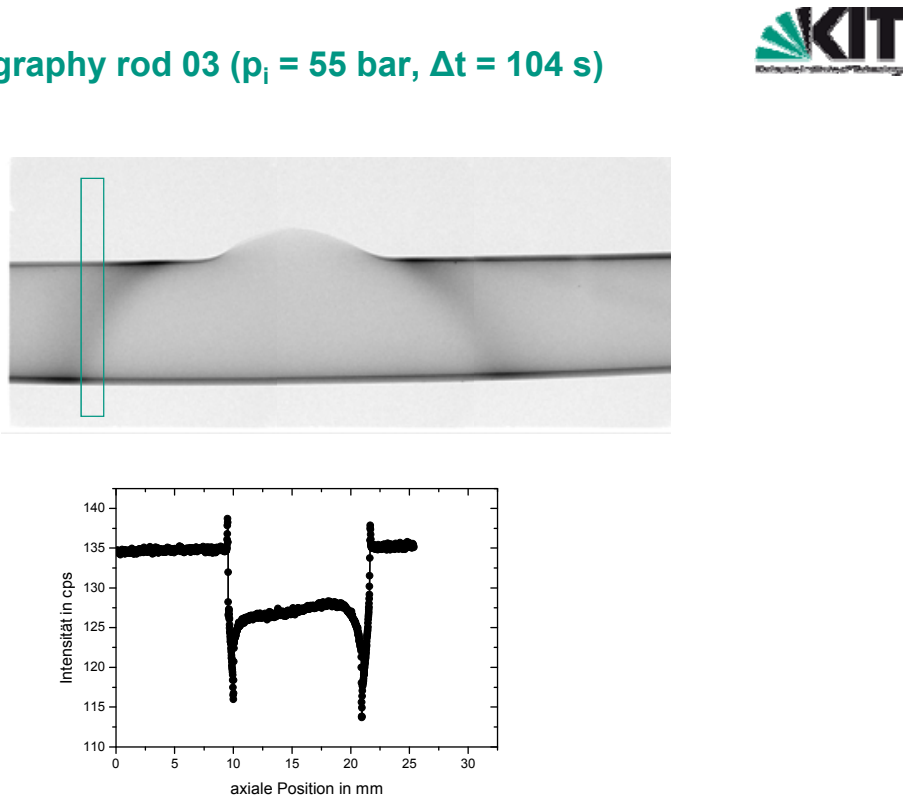

10/14 E-MRS - MRS Bilateral Energy Conference, Nice (France), May 9 - 132011 


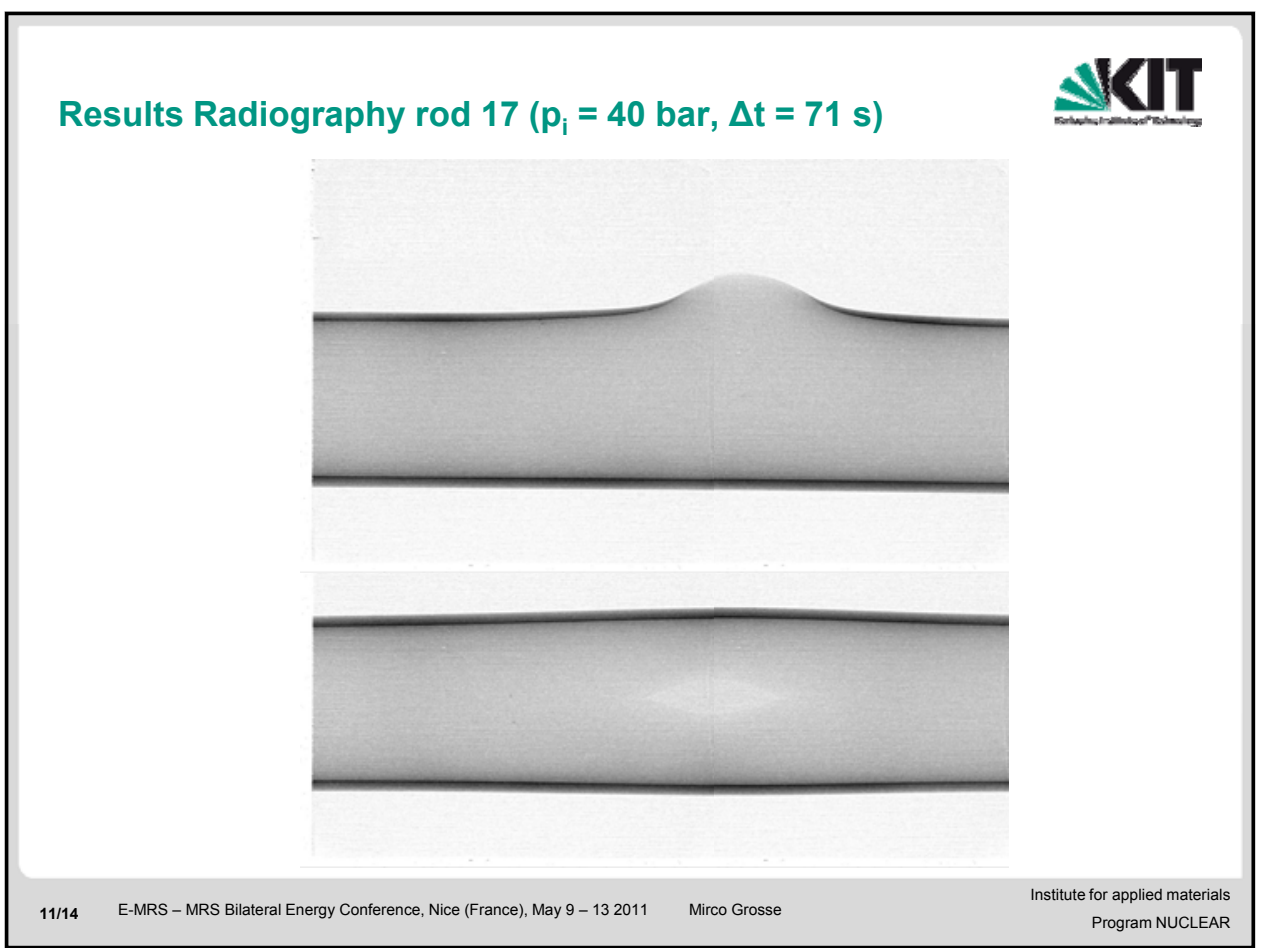

Results Tomography rod $01\left(p_{i}=50\right.$ bar, $\left.\Delta t=112 \mathrm{~s}\right)$
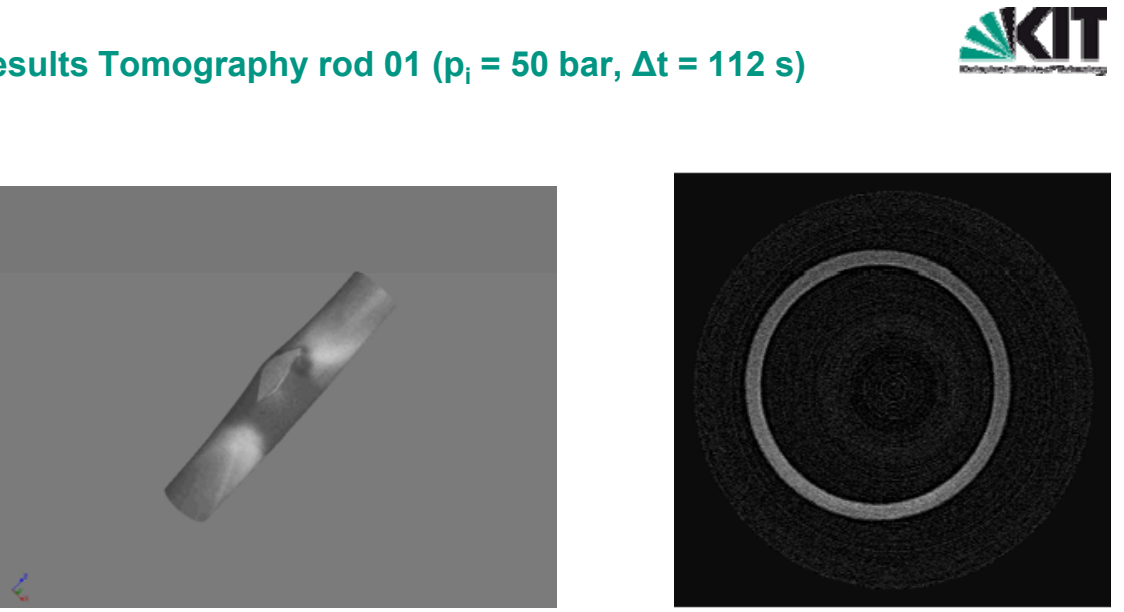

$$
x_{H}=1330 \text { wppm }
$$




\section{Summary and Conclusions}

\section{IVIT}

- Secondary hydriding was investigated by means of neutron radiography and tomography.

- The hydrogen distribution is not symmetric.

- The extension of the hydrided zone seems to depend on the time between bursting and quenching.

- Maximal hydrogen concentrations of $\sim 1300$ ppm was determined.

No influence of inner pressure or crack length is obliviously.

Strong influence of the hydrogen bands on the crack positions in the tensile tests (not shown in this presesntation)

13/14 E-MRS - MRS Bilateral Energy Conference, Nice (France), May 9-132011 Mirco Grosse Institute for applied materials

\section{Thanks}

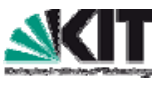

The QUENCH-LOCA tests and pre-test investigations are sponsored by the German Verein der Grosskraftwerksbetreiber VGB

KIT:

The QUENCH team, particularly C. Goulet,

J. Moch, C. Roessger and M. Walter (mechanical tests)

PSI:

S. Hartmann 